\title{
Behavioral responses of two deep-sea fish species to red, far-red, and white light
}

\author{
Erika H. Raymond ${ }^{1,2, *}$, Edith A. Widder ${ }^{1}$ \\ ${ }^{1}$ Ocean Research \& Conservation Association, 1420 Seaway Dr., Fort Pierce, Florida 34949, USA \\ ${ }^{2}$ Monterey Bay Aquarium Institute, 7700 Sandholdt Road, California 95039, USA
}

\begin{abstract}
The relatively unobtrusive deep-sea camera system Eye-in-the-Sea (EITS) was deployed in Monterey Bay Canyon, California, USA, to assess the relative photosensitivity of 2 deepsea fishes, Coryphaenoides acrolepis and Anoplopoma fimbria. Previous studies addressing the in situ response of deep-sea fishes to red and white light were done in the presence of ROV-induced stimuli. Here, we report on the behavioral response of $C$. acrolepis and A. fimbria in a vehicle-free environment when subjected to white (full visible spectrum), red (685 nm), and far-red (695 nm) illumination in situ. Under far-red light conditions, A. fimbria spent significantly more time in the fieldof-view and demonstrated an increase in entrances/exits when compared to the situation under red-light and white-light conditions. No significant difference in the average time C. acrolepis spent in the field-of-view was found between any of the test wavelengths; however, the entrances-to-exits ratio for $C$. acrolepis decreased during white-light conditions. While A. fimbria often displayed a flight response at the onset of white and sometimes red $(685 \mathrm{~nm})$ illumination, C. acrolepis did not demonstrate a similar behavioral response when exposed to light within its range of visual sensitivity. A. fimbria undergo a dramatic ontogenic shift in depth, inhabiting well-lit, near-shore waters as juveniles and moving into deeper waters as adults. It is thought that $C$. acrolepis spend part of their early life history in the light-limited mesopelagic, below the permanent thermocline, and move into deeper waters as they mature. Based on the results of the present study, we hypothesize that systematic differences in the phototactic responses of deep-sea fishes are a function of life history as well as spectral sensitivity.
\end{abstract}

KEY WORDS: Deep sea $\cdot$ Red light $\cdot$ Fish behavior

\section{INTRODUCTION}

High pressure, lack of light, and limited access to deep collection sites all present serious challenges to the sampling and/or observation of deep-sea fishes (Smith \& Baldwin 1997). Difficulty in net-sampling deep-sea fishes without significant modification or damage to their physiology has generally precluded laboratory-based behavioral studies. In situ collection methods (e.g. submersibles, remotely operated vehicles [ROVs]), on the other hand, rely on bright white (full visible spectrum) lights, which may cause irreversible retinal damage to the animal of interest (Douglas et al. 1995, Herring et al. 1999). Sampling devices such as traps, which block out light while maintaining constant pressure and temperature, have proven valuable (Childress et al. 1978, Phleger et al. 1979, Wilson \& Smith 1985), but typically involve small sample sizes and small specimens/species. As a result, arguments have been made for the value of in situ video and still imagery capture via vehicle-free or 'lander' systems (Phleger \& Soutar 1971, Priede \& Merrett 1996, Priede et al. 1998). Baited cameras are highly effective at attracting scavengers and subsequent predators, which may be drawn in by the resulting chemosensory and perhaps mechanosensory stimuli (Wilson \& Smith 1984, Smith 1985, Priede \& Smith 1986, Henriques et al. 2002). Many of the vehicle-free camera systems 
used to obtain images of the deep are also equipped with bright white illuminators; however, these illuminators are typically used as intermittent strobes and likely result in only a periodic effect (Wilson \& Smith 1984, Priede et al. 1998). Red light as a form of unobtrusive illumination has been employed in multiple shallow-water studies (Jury et al. 2002, Mills et al. 2005) and a few deep-sea studies (e.g. Widder et al. 2005).

In the present study a relatively unobtrusive video observation system, the Eye-in-the-Sea (EITS) (Widder et al. 2005) was used to record the response of deepsea animals to different wavelengths of light in situ. The vast majority of deep-sea fishes possess a single visual pigment, with maximal sensitivity in the bluegreen region of the visible spectrum (Douglas et al. 1995), which coincides with the available wavelengths of light from attenuated surface radiance and bioluminescence (Denton 1990). Electrophysiological, morphological, and some behavioral studies have indicated that most deep-sea fishes have limited sensitivity to longer wavelengths (Partridge et al. 1988, Douglas \& Partridge 1997, Widder et al. 2005). However, a few genera (Pachystomias, Aristostomias, and Malacosteus) in 1 family of meso-/bathypelagic fishes, are known to produce far-red bioluminescence and to have longwave visual sensitivity (O'Day \& Fernandez 1974, Widder et al. 1984, Bowmaker et al. 1988, Partridge et al. 1989, Partridge \& Douglas 1995), and the possibility cannot be discounted for some others (Douglas et al. 2002).

Widder et al. (2005) demonstrated that the deep-sea fish Anoplopoma fimbria (sablefish, Anoplopomatidae) responded to red light in situ even though this species has a maximum visual sensitivity at $491 \mathrm{~nm}$ (Ali \& Wagner 1975). From these results it appeared that sablefish were able to detect long-wave (680 nm) light; although, how far into the far-red spectrum that sensitivity extended was not clear. Widder et al. (2005) carried out observations with a single illuminator, making it impossible to test the response of deep-sea fishes to $>1$ wavelength of illumination during a given deployment. In order to overcome this limitation, we added an additional illuminator to the EITS system for the purposes of comparing effects of different wavelengths of illumination.

Here, we describe the behavioral response of 2 deep-water species, the Pacific grenadier Coryphaenoides acrolepis (Macrouridae) and the previously mentioned sablefish Anoplopoma fimbria to white, red, and far-red illumination. Both species were frequently recorded at our study sites in
Monterey Bay, California, USA. C. acrolepis is a common benthopelagic, mid-slope species (Cohen et al. 1990) thought to spawn at depth (Phleger 1971, Stein \& Pearcy 1982). Buoyant eggs float up to depths below $200 \mathrm{~m}$ and develop in the midwater until settling in the benthopelagic as juveniles. Studies suggest that, compared to the well-developed olfactory system, vision may play a minor role in the feeding strategies of certain adult macrourid species, such as C. armatus (Wagner 2002, 2003). One proposed explanation for the large eyes of adult macrourids is to locate the perianal light organ of potential mates (Okamura 1970). A. fimbria, also benthopelagic, is found in surface and near-shore waters during early life-history stages and migrates to deeper waters as adults (Armstrong 1996). In order to assess the relative photosensitivity of these species, we recorded their behavior when subjected to white, $\operatorname{red}(\lambda \max =685 \mathrm{~nm})$, and far-red $(\lambda \max =$ $695 \mathrm{~nm}$ ) illumination in situ.

\section{MATERIALS AND METHODS}

Equipment. EITS, Ver. 2.0, was used to record deepsea video during this study. EITS is an autonomous deep-sea viewing platform designed for deployment down to $1000 \mathrm{~m}$ from a ROV or submersible (Fig. 1). The basic EITS system consisted of red-light illumination in conjunction with an intensified camera, photomultiplier tube (PMT) trigger, an onboard computer, data storage, and custom-programmable software. In order to compensate for the low-light conditions due

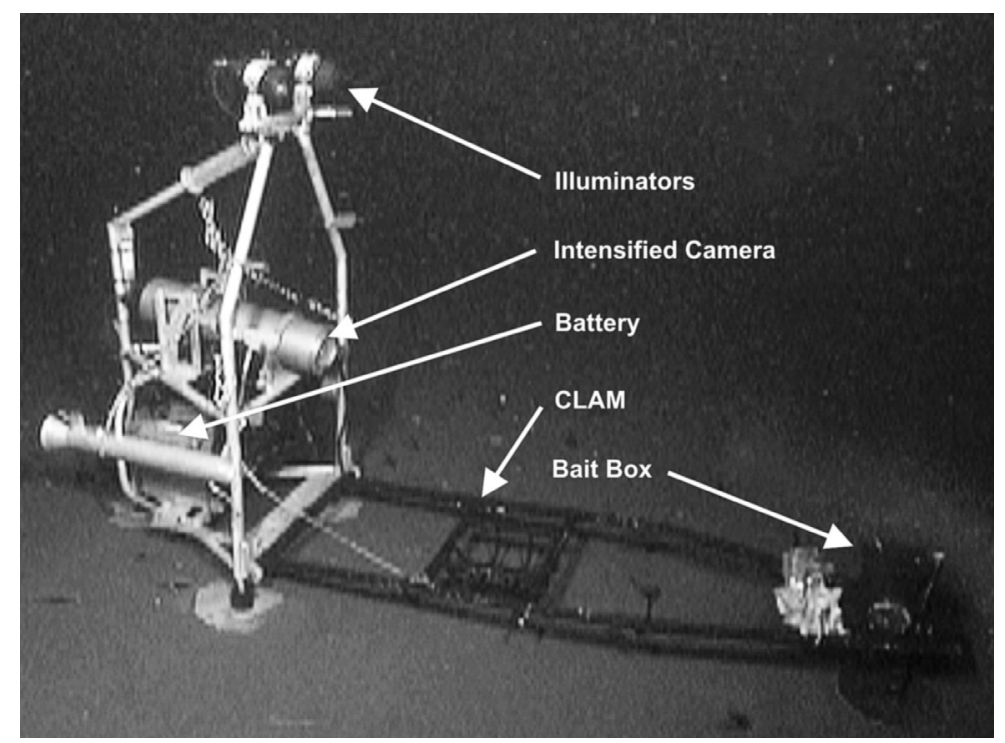

Fig. 1. In situ image of Eye-in-the-Sea (EITS) deployed in Monterey Bay, California. Bait was attached to the framework of the cannibalized ladder alignment mechanism (CLAM) and inserted into the bait box. Image provided by MBARI/ROV 'Ventana'. Viewing platform length: $2.5 \mathrm{~m}$; height: $2.2 \mathrm{~m}$ 
to red-light attenuation, an intensified CCD camera (ITT 880, ITT Industries Corporation) with extended sensitivity in the blue range was used. The camera was fitted with a $2.54 \mathrm{~cm} \mathrm{f/0.95} \mathrm{lens,} \mathrm{with} \mathrm{a} \mathrm{fixed} \mathrm{focal}$ length of $25 \mathrm{~mm}$.

Ancillary devices on the EITS included an electronic jellyfish (E-jelly) capable of imitating 5 different luminescent displays, and a hydrophone. While on deck, the EITS's data storage and software program were accessible through an Ethernet communication port. All parameters (illuminators, E-jelly, recording period and frequency, time and trigger mode) were fully programmable by the user. Video from the CCD camera was streamed to an onboard PC-104 capture card and stored directly on an 80 GB hard drive using a MPEG 4 compression format. The system was mounted on an aluminum tripod frame and powered by a $24 \mathrm{~V}$ rechargeable, lead acid Seabattery (DeepSea Power \& Light) (Fig. 1). A bait box was fastened to a foldable bait alignment frame, the cannibalized ladder alignment mechanism (CLAM), $2 \mathrm{~m}$ away from the camera (Fig. 1). During the present study, 2 independently operated LED illuminators were used. Illuminators were fitted with red LEDs (685 nm), red LEDs with a high-pass filter (695 nm), or white LEDs.

Spectral measurements. The spectral irradiances of the EITS's red illuminators were measured in air with a spectroradiometer (OL 754 UV-Vis, Optronic Laboratories). Each red illuminator package comprised of 40 red (685 nm) LEDs and an optional filter slot. A long wave pass filter glass substitute (Corion), with a peak transmission at $711 \mathrm{~nm}$, was used to reduce shortwavelength emissions. White illuminators consisted of 35 white LEDs. Illuminators were aligned on an optics bench $2 \mathrm{~m}$ away from the spectroradiometer and powered by a $12 \mathrm{~V}$ DC/1 amp bench-top power supply. Spectral irradiance of the white, red, and far-red illuminators were recorded (400 to $750 \mathrm{~nm}$ ) at $5 \mathrm{~nm}$ intervals.

Using Smith \& Baker's (1981) diffuse attenuation coefficients, $K$, for irradiance in the clearest ocean waters, irradiance at $2 \mathrm{~m}$ from the illuminators in water, $E(\lambda)_{\mathrm{w}}$, was calculated as:

$$
E(\lambda)_{\mathrm{w}}=E(\lambda)_{\mathrm{a}} \mathrm{e}^{-K z}
$$

where $z$ is the distance from the illuminator and $E(\lambda)_{a}$ is the in-air irradiance, from 400 to $750 \mathrm{~nm}$ at a distance of $2 \mathrm{~m}$.

In water the red illuminator had a peak irradiance of $2.47 \times 10^{-7} \mathrm{~W} \mathrm{~cm}^{-2} \mathrm{~nm}^{-1}$ at $685 \mathrm{~nm}$, and the far-red illuminator had a peak irradiance of $1.64 \times 10^{-8} \mathrm{~W} \mathrm{~cm}^{-2}$ $\mathrm{nm}^{-1}$ at $695 \mathrm{~nm}$, whereas the white illuminator had a broad spectral distribution with a peak irradiance of $9.03 \times 10^{-9} \mathrm{~W} \mathrm{~cm}^{-2}$ in the blue region (465 nm) (Fig. 2) Total irradiance values for white, red, and far-red illuminators were $1.4 \times 10^{-7}, 1.35 \times 10^{-6}$, and $7.51 \times 10^{-8} \mathrm{~W}$ $\mathrm{cm}^{-2}$, respectively.

Study sites and experimental conditions. During fall 2005, spring 2006, and fall 2006, the EITS was deployed at 3 sites in Monterey Bay for a total of 6 dives (Table 1). All deployments were done with Monterey Bay Aquarium Research Institute's (MBARI) hydraulically powered ROV 'Ventana', deployable to depths of $2300 \mathrm{~m}$. The ROV's swing arm stabs (suspension arms) held the camera in position during the deployment and recovery dives. Deployments were made using baited traps and the E-jelly optical lure. Carcasses from local fish species

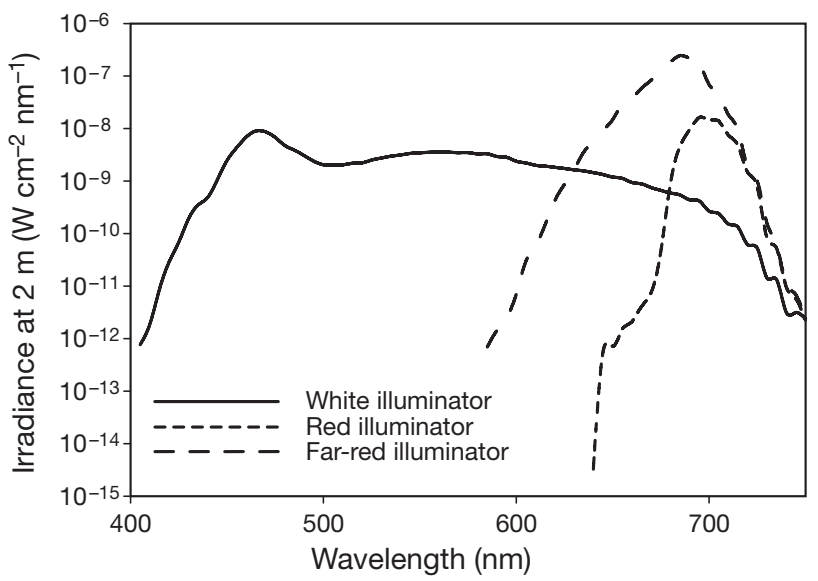

Fig. 2. Radiometric recordings for illuminators. Measured peak intensity wavelengths in water at $2 \mathrm{~m}$ from EITS illuminators occurred at: white $(465 \mathrm{~nm})$, red $(685 \mathrm{~nm})$, and far red $(695 \mathrm{~nm})$

Table 1. EITS deployment specifications. Note: Total recording time only includes timed events when a single illuminator was on, with the exception of 9 September 2005, during periods of no electronic jellyfish activity

\begin{tabular}{|c|c|c|c|c|c|c|c|}
\hline \multirow{2}{*}{$\begin{array}{l}\text { Dive } \\
\text { No. }\end{array}$} & \multirow{2}{*}{ Date } & \multicolumn{2}{|c|}{ Dive site coordinates } & \multirow{2}{*}{$\begin{array}{l}\text { Depth } \\
\text { (m) }\end{array}$} & \multirow{2}{*}{$\begin{array}{l}\text { Deployment } \\
\text { period }(\mathrm{h})\end{array}$} & \multirow{2}{*}{$\begin{array}{l}\text { Total recording } \\
\text { time (min) }\end{array}$} & \multirow{2}{*}{$\begin{array}{c}\text { Illuminators } \\
(\lambda)\end{array}$} \\
\hline & & Latitude & Longitude & & & & \\
\hline 1 & 19 Sep 2005 & $36^{\circ} 44.15^{\prime} \mathrm{N}$ & $122^{\circ} 02.813^{\prime} \mathrm{W}$ & 636 & 24 & 468 & $695 \mathrm{~nm}$ \\
\hline 2 & 20 Sep 2005 & $36^{\circ} 44.111^{\prime} \mathrm{N}$ & $122^{\circ} 02.758^{\prime} \mathrm{W}$ & 641 & 48 & 120 & $680 \mathrm{~nm}, 695 \mathrm{~nm}$ \\
\hline 3 & 22 Sep 2005 & $36^{\circ} 45.606^{\prime} \mathrm{N}$ & $121^{\circ} 59.608^{\prime} \mathrm{W}$ & 626 & 24 & 264 & $680 \mathrm{~nm}, 695 \mathrm{~nm}$ \\
\hline 4 & 18 May 2006 & $36^{\circ} 42.708^{\prime} \mathrm{N}$ & $122^{\circ} 11.239^{\prime} \mathrm{W}$ & 882 & 48 & 110 & $680 \mathrm{~nm}, 695 \mathrm{~nm}$ \\
\hline 5 & 22 May 2006 & $36^{\circ} 42.685^{\prime} \mathrm{N}$ & $122^{\circ} 11.319^{\prime} \mathrm{W}$ & 888 & 48 & 123 & $680 \mathrm{~nm}, 695 \mathrm{~nm}$ \\
\hline 6 & 28 Sep 2006 & $36^{\circ} 42.360^{\prime} \mathrm{N}$ & $122^{\circ} 09.95^{\prime} \mathrm{W}$ & 888 & 48 & 383 & White, $695 \mathrm{~nm}$ \\
\hline
\end{tabular}


were used as bait. Fish heads and backbones were strapped to the CLAM's black aluminum frame. Larger chunks of fish flesh were placed in a flow-through black plastic bait box, which had $6.0 \mathrm{~mm}$ wide slits along the sides and top. When possible, the system was aligned so that direction of Camera view was acrosscurrent at the time of deployment. The system was programmed to run in both timed and timed/triggered mode. Upon recovery, all video clips were downloaded from the EITS to a topside laptop computer and stored for later analyses. The EITS was programmed to record for 1 min at 5 min intervals, starting during the ROV deployment period. The program ran until the EITS was recovered or the system's battery life was exceeded, typically 30 to $36 \mathrm{~h}$ after deployment on the seabed. Illuminators were programmed to turn on at the start of the 1 min recording period and turn off at the end of the 1 min recording period. Red-light experiments consisted of $1 \mathrm{~min}$ of red illumination every $5 \mathrm{~min}$ over a 30 min interval, followed by 1 min of far-red illumination for the same recording interval. This program (red, dark, red, dark followed by far-red, dark, far-red, dark) was repeated multiple times throughout each mission. A white- versus red-light experiment was conducted in the same manner, but using far-red and white illumination. Although the E-jelly ran during portions of Dives 4 and 5, it was programmed to remain off during the red-light experimental period.

Video analysis. Only video clips from the timed mode and in the absence of the ROV were used in these analyses. A total of 1150 MPEG 4 video clips of $1 \mathrm{~min}$ each were analyzed. Type and number of deep-sea species were recorded. When Coryphaenoides acrolepis or Anoplopoma fimbria were present (Fig. 3), 3 activities were noted in each 1 min block for both species: (1) time spent in the field-of-view, (2 the number individuals entering the field-of-view, and (3) and the number of individuals exiting the fieldof-view. Due to differences in depth-of-field between the white, red, and far-red illuminators, only fish swimming between the camera and the bait container at the end of the CLAM were used in the final analyses, in order to standardize the volume viewed between the 2 different viewing regimes. The field-of-view in this study was defined as $2 \mathrm{~m}$ deep by $0.84 \mathrm{~m}$ wide. Data from closely spaced deployments in time at the same study site were pooled for analysis. Statistical analysis was performed applying Winstat ${ }^{\circledR}$ statistical software for Excel. The Kruskal-Wallis test was used to test for a normal distribution. Data were not normally distributed, and differences in time spent in the field-of-view during periods of unfiltered $(685 \mathrm{~nm})$ and filtered (695 nm) illumination were analyzed for significance using the Mann-Whitney $U$-test. Values were considered significant at $\mathrm{p}<0.05$.
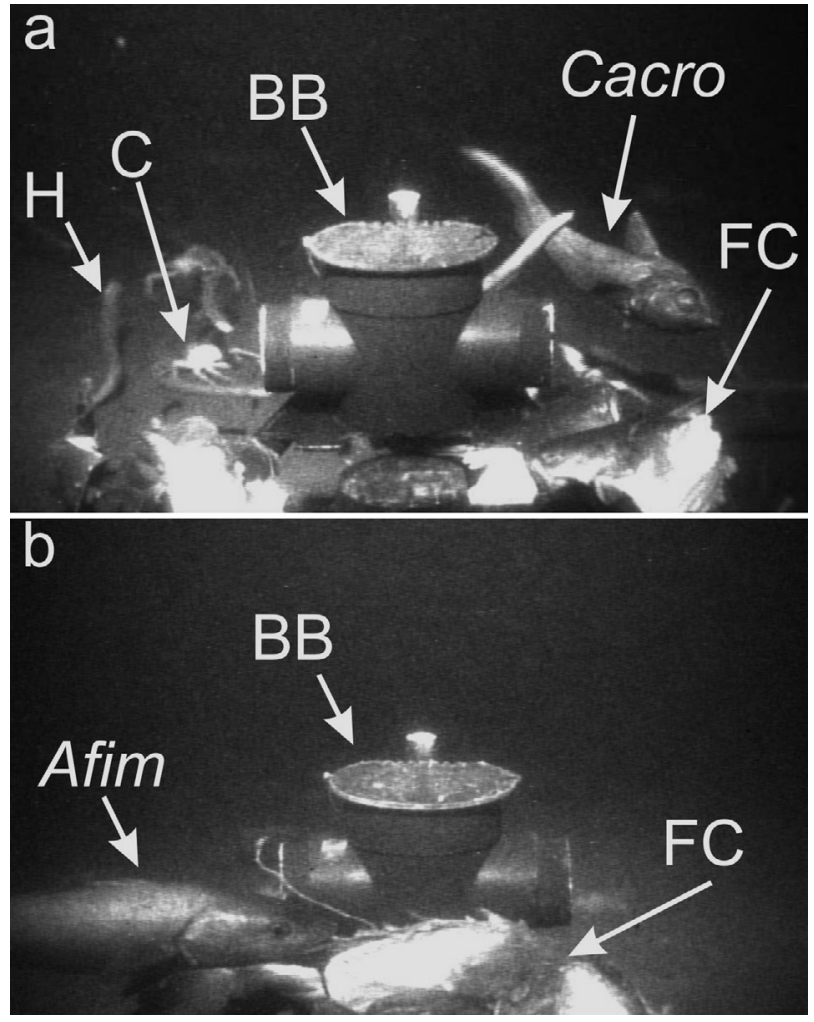

Fig. 3. Frame grabs from EITS video with red illumination. (a) Coryphaenoides acrolepis (Cacro) 18 May 2006; (b) Anoplopoma fimbria (Afim), 22 September 2005. BB: bait box; FC: fish carcass; H: hagfish; C: tanner crab

\section{RESULTS}

Species present at study sites. With the exception of Eptatretus deani (black hagfish), Anoplopoma fimbria was the most common fish species present on Dives 1 , 2,3 , and 5, whereas the most abundant megafauna during Dives 4 and 6 was Coryphaenoides acrolepis. During each study period, the number of individuals for all species present fluctuated over time. A. fimbria were frequently present early in the deployment period, but tended to drop off in numbers over time. Often they would reappear in pulses later in the deployment period. A similar pattern was detected in C. acrolepis. In addition to C. acrolepis, A. fimbria, and E. deani, other fish species seen around the study site included Somniosus pacificus (Pacific sleeper shark), Antimora microlepis (finescale mora), and Apristurus sp. (cat shark). Since these species were observed infrequently, they were not included in the quantitative behavioral analysis.

Coryphaenoides acrolepis activity in red light. A Mann-Whitney $U$-test on the average amount of time C. acrolepis spent on camera in the presence of red versus far-red illumination indicated there was no sig- 
nificant difference (Fig. 4a). Moreover, there was no prominent difference in the ratio of $C$. acrolepis entrances to exits between illumination conditions (Fig. 4b). Under both illumination conditions, C. acrolepis appeared undisturbed and, unless bumped by another individual, rarely displayed startled behavior.

Since a current meter was unavailable during this study, drift direction of marine snow and loose pieces of bait were used as an indicator of current direction. It was observed that most of the macrourids aligned themselves with the current and approached the bait from the down-current direction. Once Coryphaenoides acrolepis approached the CLAM, they would frequently maintain a position downstream of the bait container, with their heads pointing upstream.

Anoplopoma fimbria activity in red light. Data from Dives 2 and 3 revealed a significant difference in the average time $A$. fimbria spent in the field-of-view under the 2 illumination conditions (Fig. 4c). Although there was no statistical difference $(p=0.28)$ in average time on camera during Dives 4 and 5, there was a considerable difference in entrances to exits, indicating a tendency for $A$. fimbria to avoid the study site under red illumination. Throughout Dive 4, A. fimbria were not present in the field-of-view during periods of red illumination. A. fimbria data had a consistent pattern of smaller ratios of entrances to exits during periods of red illumination (Fig. 4d). To test the effect of changes in illumination intensity at the same wavelength on fish behavior, we fitted both illuminators with the $711 \mathrm{~nm}$ filter and used them simultaneously during the 1 min recording periods on Dive 1. During this experiment, the average amount of time individual $A$. fimbria were detected in the field-of-view, $16.7 \mathrm{~s}$, was comparable to the single illuminator at $695 \mathrm{~nm}$ average,
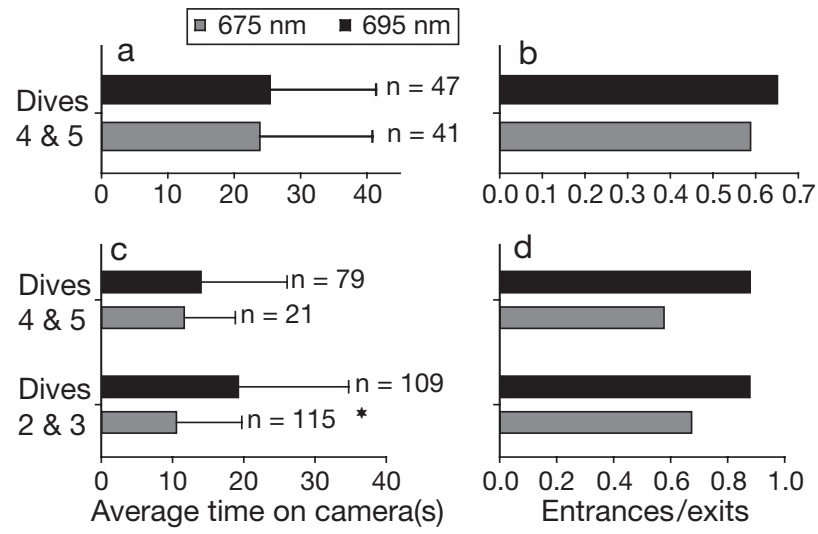

Fig. 4. (a,b) Coryphaenoides acrolepis and (c,d) Anoplopoma fimbria. $(\mathrm{a}, \mathrm{c})$ Average time spent in the field-of-view and $(\mathrm{b}, \mathrm{d})$ the ratio of entrances to exits during periods of red illumination (gray) and far-red illumination (black). No. of ind. viewed under each condition displayed at end of bars. ${ }^{*}$ Significantly different pair (Mann-Whitney $U$-test: $p<0.05$ )

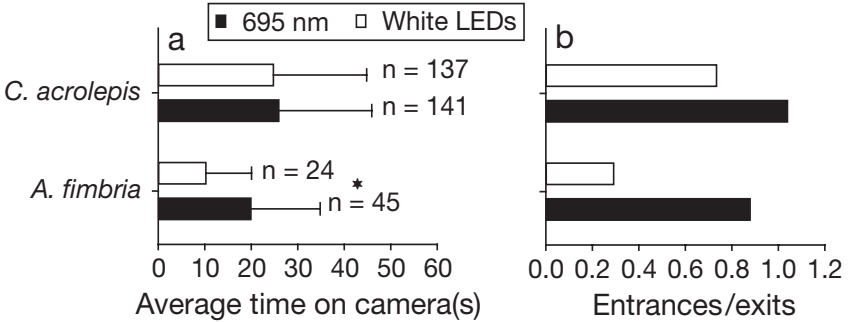

Fig. 5. Coryphaenoides acrolepis and Anoplopoma fimbria. (a) Average time spent in the field-of-view and (b) the ratio of entrances to exits during periods of far-red illumination (black) and white illumination (white), 28 September 2006. No. of ind. viewed under each condition displayed at end of bars. ${ }^{*}$ Significantly different pair (Mann-Whitney $U$-test: $\mathrm{p}<0.05)$

17.4 s, on Dive 2, but lower than the average of Dive 3, $23.7 \mathrm{~s}$.

Four primary behavioral patterns were observed for Anoplopoma fimbria: (1) rapidly swimming through the field-of-view, which was commonly seen during the initial deployment period; (2) active and aggressive feeding on the bait; (3) a rapid turn in swimming direction or abrupt cessation of feeding within the first 1 or $2 \mathrm{~s}$ of red illumination; and (4) a slow meandering around the periphery of the circle of illumination when the red illuminator was on. Aggressive feeding behavior was most prevalent during, but not limited to, periods of far-red illumination.

White- versus red-light experiments. Both Coryphaenoides acrolepis and Anoplopoma fimbria were observed at the study site during Dive 6. The swimming pattern of $A$. fimbria was noticeably different during periods of white illumination. A. fimbria were frequently observed darting outside the field-of-view at the onset of the white illumination period. For $A$. fimbria there was a significant decrease in average time spent on camera during white-light exposure; however, in the C. acrolepis assemblage there was no significant difference in the average time spent in the field-of-view between light treatments (Fig. 5a). A decrease in the entrances-to-exits ratio during periods of white light was observed in both species (Fig. 5b), indicating an avoidance of the study site under whitelight illumination.

\section{DISCUSSION}

Analysis of Anoplopoma fimbria and Coryphaenoides acrolepis swimming behavior during periods of white, red (685 nm), and far-red (695 nm) illumination indicated that both species respond minimally to longer wavelengths of red light; however, responses to these wavelengths of light were species specific. 
A. fimbria often spent significantly more time in the field-of-view during periods of far-red illumination, whereas C. acrolepis behavior was not statistically different when exposed to shorter and longer wavelengths of red light. The decrease in A. fimbria time on camera during red- and white-light conditions is consistent with their known range of visual sensitivity in situ (Widder et al. 2005).

Results from the present study show that deep-sea fishes tend to avoid regions of illumination within their range of detection. The entrances-to-exits ratio was used as a species-specific proxy for the degree of response to illumination wavelength. A ratio well below 1 indicated aversion to each wavelength, whereas a high ratio $(>1)$ indicated attraction to specific wavelengths. Anoplopoma fimbria assemblages consistently had lower entrances-to-exits ratios during periods of red- or white-light illumination, while ratio values close to 1 during exposure to far-red light indicate minimal disturbance or detection at that wavelength of illumination. A. fimbria were frequently observed skirting the field-of-illumination's periphery under white and red conditions, but we did not note the same type of avoidance behavior from individual Coryphaenoides acrolepis during any illumination condition. Although entrances-to-exits ratios for C. acrolepis did not indicate a strong behavioral response to the red wavelengths used in this study, there was a slight decrease in the ratio values when white light was present.

The visual systems of Anoplopoma fimbria and Coryphaenoides acrolepis have adapted to the spectral quality of the depths they inhabit. The intensity and spectral quality of light changes with depth, and, in optically clear waters, blue light travels the furthest (Jerlov 1976). Since deeper waters are devoid of red light, with the exception of biologically produced red light, which is made available by a very limited number of fish species (Widder et al. 1984), visual pigments of deep-sea fishes have a wide absorption spectrum and, as a result, capture light from a broad emission range (Bowmaker et al. 1994). Below depths where sunlight can penetrate, bioluminescence is the only source of illumination. Montgomery \& Pankhurst (1997) make the argument that the type of visual sensitivity required for surface light detection in the mesopelagic zone is also well adapted for detection of bioluminescence in the aphotic zone. A. fimbria undergo a dramatic ontogenic shift in depth. As juveniles, A. fimbria live in well-lit, near-shore surface waters and move off shore and into the light-limited environment of the deep sea as adults (Armstrong 1996). Life in such a dynamic depth range and light regime (Armstrong 1996) requires a broad sensitivity spectrum. Conversely, C. acrolepis primarily inhabit depths devoid or nearly devoid of sunlight. The flight reaction we observed in A. fimbria during periods with shorter wavelengths of light could potentially be a hardwired response as a method of predator avoidance in the well-lit surface waters during early development. This could also explain why we do not seem to see the same type of response from a deep-dwelling species like C. acrolepis.

Anoplopoma fimbria actively avoid white illumination compared to red illumination. This study confirms findings by Widder et al. (2005) that $A$. fimbria respond adversely to periods of white illumination as indicated by a decrease in the average time on camera and a lower ratio of entrances to exits. In a study by Wilson \& Smith (1984), Coryphaenoides spp. behavior appeared unaltered by the presence of white illumination, as it was shown not to act as an attractant in the absence of bait nor did it deter fish from the viewing area during baited studies. The $C$. acrolepis present in this study were not attracted to the field-of-view during whitelight conditions, and the decreased ratio in entrances to exits demonstrated avoidance during this time. Presented with white illumination clearly within their range of detection, $C$. acrolepis do not appear to respond to the same degree as $A$. fimbria. In the adult stages of life, certain macrourid species likely rely on olfaction and mechanoreception to find food sources and possibly use vision to find mates or, to a lesser extent, food (Wagner 2002, 2003). Bailey et al. (2007) suggested that grenadiers use olfaction to locate food sources from a distance, but rely on gustation and mechanoreception at close ranges to the source. It is possible that vision plays a minor role in the feeding ecology of adult $C$. acrolepis.

Coryphaenoides acrolepis and Anoplopoma fimbria are frequently observed around artificial food falls (Isaacs \& Schwartzlose 1975, Smith 1985). Drazen et al. (2001) suggested that scavenged material may be an important component in the diet of adult C. acrolepis and could account for up to $20 \%$ of their total food consumption. Laboratory experiments conducted by Smith (1978) using hyperbaric chambers have revealed low metabolic rates in macrourids. Limited food availability in deep-sea benthic zones and predator avoidance are competing factors in metabolic requirements. A. fimbria are capable of sustaining long periods of food depravation (Sullivan \& Smith 1982), likely an adaptation to the periodic nature of food availability in the deep sea. Lokkeborg et al. (1995) demonstrated that response to a low-concentration odor plume was higher in food-deprived A. fimbria, whereas satiated individuals spent the majority of their time resting on the bottom, away from the light during periods of exposure to odor plumes. We propose that the observed A. fimbria behavior around our baited camera was the result of competing sensory inputs. During 
periods of white and red illumination, vision outweighed olfactory cues; however, at wavelengths near the upper limit of their sensitivity range, A. fimbria were influenced primarily by olfaction and their level of starvation.

One of the limitations of red-light illumination in the ocean is the decreased range compared to white-light systems. We worked around this shortcoming by using an intensified camera. This solution had the added benefit of enabling us to record in situ naturally bioluminescent events. Bioluminescent events were rarely detected during timed recording periods and were normally the result of mechanical disturbances during feeding events. Sea whips Halipteris californica and sea pens Umbellula sp. were likely the main sources of observed bioluminescence.

Intensity of the red-illumination source dropped by more than an order of magnitude with the addition of the $711 \mathrm{~nm}$ high-pass filter. Although we limited analyzed observations to a distance of $2 \mathrm{~m}$ from the camera, fauna were often detected at greater distances from the system. In previous deployments, in which both illuminators were fitted with high-pass filters and operated in unison, a greater field-of-view of up to $4 \mathrm{~m}$ from the camera was possible, and there was no discernable difference between the average amount of time Anoplopoma fimbria spent in the field of view under different levels of intensity at the same wavelength $(695 \mathrm{~nm})$. Future deployments will involve the use of both illuminators fitted with high-pass filters given that 2 far-red illuminators provide sufficient lighting and species observed to date appear minimally affected by this illumination.

Based on the results of the present study, the benefits of the EITS 2.0 system for deep-ocean behavioral experiments are: (1) it is a relatively unobtrusive viewing platform, free from ship noise and white light; (2) it can be positioned to view specific areas of interest, including fragile habitats such as thickets of deep coral; (3) it can be equipped with up to 3 light sources of different wavelengths and programmed to come on in different combinations; and (4) it can be deployed for multiple days at a time. There are tradeoffs between attenuation of light in water, camera sensitivity, and animal sensitivity when conducting unobtrusive observations in the deep sea. Data presented here and in Widder et al. (2005) suggest that, although lower wavelengths of red light are detectable by some deepsea species, far-red light (695 nm) is sufficiently unobtrusive for most deep-sea applications.

Acknowledgements. This research was supported in part by MBARI and NSF OCE-0451333. We thank L. Frey, D. Smith, and T. Cimaglia for assistance with engineering efforts and ship operations. MBARI/ROV 'Ventana pilots', RV 'Pt. Lobos' crew, R. Sherlock and M. Conway at MBARI provided valu- able shipboard and land-based assistance. We are indebted to T. Sutton for assistance with species identifications and critical reading of the manuscript.

\section{LITERATURE CITED}

Ali MA, Wagner HJ (1975) Visual pigments: phylogeny and ecology. In: Ali MA (ed) Vision in fishes. Plenum Press, New York, p 481-515

Armstrong RH (1996) Alaska's fish. A guide to selected species. Alaska Northwest Books, Seattle, WA

Bailey DM, Wagner HJ, Jamieson AJ, Ross MF, Priede IJ (2007) A taste of the deep-sea: the roles of gustatory and tactile searching behaviour in the grenadier fish Coryphaenoides armatus. Deep-Sea Res I 54:99-108

Bowmaker JK, Dartnall HJA, Herring PJ (1988) Longwavesensitive visual pigments in some deep-sea fishes: segregation of 'paired' rhodopsins and porphyropsins. J Comp Physiol A 163:685-698

Bowmaker JK, Govardovskii VI, Shukolyukov SA, Zueva LV, Hunt DM, Sideleva VG, Smirnova OG (1994) Visual pigments and the photic environment: the cottoid fish of Lake Baikal. Vision Res 34:591-605

Childress JJ, Barnes AT, Quetin LB, Robison BH (1978) Thermally protecting cod ends for the recovery of living deep-sea animals. Deep-Sea Res 25:419-422

Cohen DM, Inada T, Iwamoto T, Scialabba N (1990) FAO species catalogue, No. 125, Vol. 10. Gadiform fishes of the world (order Gadiformes): an annotated and illustrated catalogue of cods, hakes, grenadiers and other gadiform fishes known to date. FAO Fish Synop, FAO, Rome

Denton EJ (1990) Light and vision at depths greater than 200 metres. In: Herring PJ, Campbell AK, Whitfield M, Maddock L (eds) Light and life in the sea. Cambridge University Press, Cambridge, p 127-148

Douglas RH, Partridge JC (1997) On the visual pigments of deep-sea fish. J Fish Biol 50:68-85

Douglas RH, Partridge JC, Hope AJ (1995) Visual and lenticular pigments in the eyes of demersal deep-sea fishes. J Comp Physiol A 177:111-122

Douglas RH, Bowmaker JK, Mullineaux CW (2002) A possible retinal longwave detecting system in a myctophid fish without far-red bioluminescence; evidence for a sensory arms race in the deep-sea. In: Stanley PE, Kricka LJ (eds) Bioluminescence and chemiluminescence: progress and current applications. World Scientific Publishing, Singapore, p 391-394

Drazen JC, Buckley TW, Hoff GR (2001) The feeding habits of slope dwelling macrourid fishes in the eastern North Pacific. Deep-Sea Res I 48:909-935

Henriques C, Priede IG, Bagley PM (2002) Baited camera observations of deep-sea demersal fishes of the northeast Atlantic Ocean at $15-28^{\circ} \mathrm{N}$ off West Africa. Mar Biol 141: 307-314

Herring PJ, Gaten E, Shelton PMJ (1999) Are vent shrimps blinded by science? Nature 398:116

Isaacs JD, Schwartzlose RA (1975) Active animals of the deep-sea floor. Sci Am 233:84-91

Jerlov NG (1976) Marine optics. Elsevier Scientific Publishing Company, New York

Jury SH, Howell H, O'Grady DF, Watson III WH (2002) Lobster trap video: in situ video surveillance of the behaviour of Homarus americanus in and around traps. Mar Freshw Res 52:1125-1132

Lokkeborg S, Olla BL, Pearson WH, Davis MW (1995) Behavioural responses of sablefish, Anoplopoma fimbria, to bait odour. J Fish Biol 46:142-155 
Mills DJ, Verdouw G, Frusher SD (2005) Remote multicamera system for in situ observations of behaviour and predator/prey interactions of marine benthic macrofauna. NZ J Mar Freshw Res 39:347-352

Montgomery JC, Pankhurst NW (1997) Sensory physiology. In: Randall DJ, Farrell AP (eds) Deep-sea fishes. Academic Press, San Diego, CA, p 325-349

O'Day WT, Fernandez HR (1974) Aristostomias scintillans (Malacosteidae): a deep-sea fish with visual pigments apparently adapted to its own bioluminescence. Vision Res 14:545-550

Okamura O (1970) Studies on the macrouroid fishes of Japan: morphology, ecology and phylogeny. USA Mar Biol Stn 17:1-148

Partridge JC, Douglas RH (1995) Far-red sensitivity of dragon fish. Nature 375:21-22

Partridge JC, Archer SN, Lythgoe JN (1988) Visual pigments in the individual rods of deep-sea fishes. J Comp Physiol A 162:543-550

Partridge JC, Shand J, Archer SN, Lythgoe JN, van GroningenLuyben WAHM (1989) Interspecific variation in the visual pigments of deep-sea fishes. J Comp Physiol A 164:513-529

Phleger CF (1971) Biology of macrourid fishes. Am Zool 11: 419-423

Phleger CF, Soutar A (1971) Free vehicles and deep-sea biology. Am Zool 11:409-418

Phleger CF, McConnaughey RR, Crill P (1979) Hyperbaric fish trap operation and deployment in the deep sea. Deep-Sea Res 26A:1405-1409

Priede IG, Merrett NR (1996) Estimation of abundance of abyssal demersal fishes; a comparison of data from trawls and baited cameras. J Fish Biol 49:207-216

Priede IG, Smith KL Jr (1986) Behaviour of the abyssal grenadier, Coryphaenoides yaquinae, monitored using ingestible acoustic transmitters in the Pacific Ocean. J Fish Biol 29:199-206

Priede IG, Addison S, Bradley S, Bagley PM and 12 others (1998) Autonomous deep-ocean lander vehicles; modular approaches to design and operation. IEEE J Ocean Eng 3: $1238-1244$

Editorial responsibility: Howard Browman (Associate Editorin-Chief), Storebø, Norway
Smith CR (1985) Food for the deep sea: utilization, dispersal and flux of nekton falls at the Santa Catalina Basin floor. Deep-Sea Res 32:417-442

Smith CR, Baker KS (1981) Optical properties of the clearest natural waters (200-800 nm). Appl Opt 20:177-184

Smith KL Jr (1978) Metabolism of the abyssopelagic rattail Coryphaenoides armatus measured in situ. Nature 274: 362-364

Smith KL Jr, Baldwin RJ (1997) Laboratory and in situ methods for studying deep-sea fishes. In: Randall DJ, Farrell AP (eds) Deep-sea fishes. Academic Press, San Diego, CA, p 351-378

Stein DL, Pearcy WG (1982) Aspects of reproduction, early life history, and biology of macrourid fishes off Oregon, USA. Deep-Sea Res I 29:1313-1329

Sullivan KM, Smith KL Jr (1982) Energetics of sablefish, Anoplopoma fimbria, under laboratory conditions. Can J Fish Aquat Sci 39:1012-1020

Wagner HJ (2002) Sensory brain areas in the three families of deep-sea fish (slickheads, eels, and grenadiers): comparison of mesopelagic and demersal species. Mar Biol 141: $807-817$

Wagner HJ (2003) Volumetric analysis of brain areas indicates a shift in sensory orientation during development in the deep-sea grenadier Coryphaenoides armatus. Mar Biol 142:791-797

Widder EA, Latz MF, Herring PJ, Case JF (1984) Far-red bioluminescence from two deep-sea fishes. Science 225: $512-514$

Widder EA, Robison BH, Reisenbichler KR, Haddock SHD (2005) Using red light for in situ observations of deep-sea fishes. Deep-Sea Res Part I 52:2077-2085

Wilson RR Jr, Smith KL Jr (1984) Effect of near-bottom currents on detection of bait by the abyssal grenadier fishes Coryphaenoides spp., recorded in situ with a video camera on a free vehicle. Mar Biol 84:83-91

Wilson RR Jr, Smith KL Jr (1985) Live capture, maintenance and partial decompression of a deep-sea grenadier fish (Coryphaenoides acrolepis) in a hyperbaric trapaquarium. Deep-Sea Res 32:1571-1582

Submitted: December 7, 2006; Accepted: July 27, 2007

Proofs received from author(s): October 29, 2007 